\title{
The Empirical Study on Shandong Province's Level Measurement and Dynamic relationship of Integration of Informationization and Industrialization
}

\author{
Guo Siliang 1 \\ Qilu Normal University \\ Department of economics, QLNU \\ Jinan, China \\ e-mail:GSL200601@126.com
}

\author{
Diao Yanhua 2 \\ Shandong Xiehe University, \\ Department of economic management, SXU \\ Jinan, China \\ e-mail:99581735@qq.com
}

\begin{abstract}
In this paper, based on the materials between the years of 2001-2012 in Shandong province, we estimated the level of the fusion between informationization and industrialization, calculated the integration index, and quantitatively reflected the integration development level of the fusion between informationization and industrialization in Shandong Province. And then, through the establishment of VAR model, we empirical analyzed the dynamic fusionrelations in Shandong province. Finally, we proposed countermeasures and suggestions for the deep integration of informationization and industrialization in Shandong Province, in order to promote the realization of Shandong Province's development objectives, and also promoted the transformation of Shandong Province from a big economic province to a strong economic province to achieve leapfrog development of social productive forces, and provided valuable decision-making recommendation.
\end{abstract}

Keywords-Informationization; Industrialization; The fusion of informationization and industrialization;The VAR model

\section{RESEARCH BACKGROUND}

There are many theoretical studies on the integration of the informationization and industrialization and they are mainly focused on the relationship of informationization and industrialization, the connotation of the integration, the mechanisms, and promotion policies and so on. For example, Zhou Zhenhua ( 2008 ), Tong Youhao ( 2008 ), Li Jian ( 2010 ), respectively from different perspectives describe and analyze the connotation of the integration of informationization and industrialization [1][2][3]; An Xiaopeng ( 2008 ) adopts the perspective of the global industrial revolution and elaborates the integration[4]; Xu Jun ( 2008 ) conducts a theoretical analysis on the influencing factors of the integration, and brings forward some corresponding strategies[5]; Jin Jiangjun ( 2009 ) establishes a theoretical model to study the theoretical system of the integration[6]; Wang Jinjie ( 2009 ) comes up with an analytical research on China's countermeasure for integration[7]; Wang Xiwei, etc. ( 2010 ) start from the connotation of the integration and reveal the maturity models of both the development of informationization and industrialization, based on this basis, they also construct a system model of the key elements of the integration.[8] Ji Desheng, etc. ( 2012 ) explore the related issues on the deep integration in China's high-tech zone[9].

Based on the contents of the existing researches, they mainly focus on the theoretical issues of the integration and empirical analysis on the national level, but empirical analysis on the provincial and municipal levels is not enough. Therefore, this paper is based on the existing researches between the year of 2001-2012 to estimate Shandong Province's level of integration index since the last 12 years, and reflect the level of development of integration in Shandong Province, and then, through the establishment of the VAR model, empirical analysis and dynamic relationship of integration in Shandong Province is analyzed, while at the same time, combines the study with economic sense.

\section{THE MODEL AND METHOD}

\section{A. Two fusion level measure method}

Two chemical fusion levels ultimately reflected in the development of informatization and industrialization level, the two fusions the deeper, the higher the level of informatization and industrialization. Therefore, we still adopt the method of informatization and industrialization 
level, respectively, measure to reflect the two fusion levels.

\section{1) Method to measure the informatization level}

Informatization index is used to calculate the different social, national or regional level of informatization index. This paper uses model of informatization index of the Japanese Telecommunications and economic comparison of authority (RITE) proposed, the model from four secondary indicators of the amount of information, information equipment, the rate of communication subject level, information coefficient to measure the different social stages, different countries or areas of informatization development degree, under the two-level index, set up 11 tertiary indicators. In combination with the practical situation of our country and the status of the realistic society, we improved the RITE model, remove some indicators that does not reflect the current social reality, and increase some index can reflect the characteristics of the current social development. The improved RITE model contains four secondary indicators and 14 tertiary indicators, as shown in tableI.

TABLEI EVALUATION INDEX SYSTEM OF INFORMATIONIZATION LEVEL

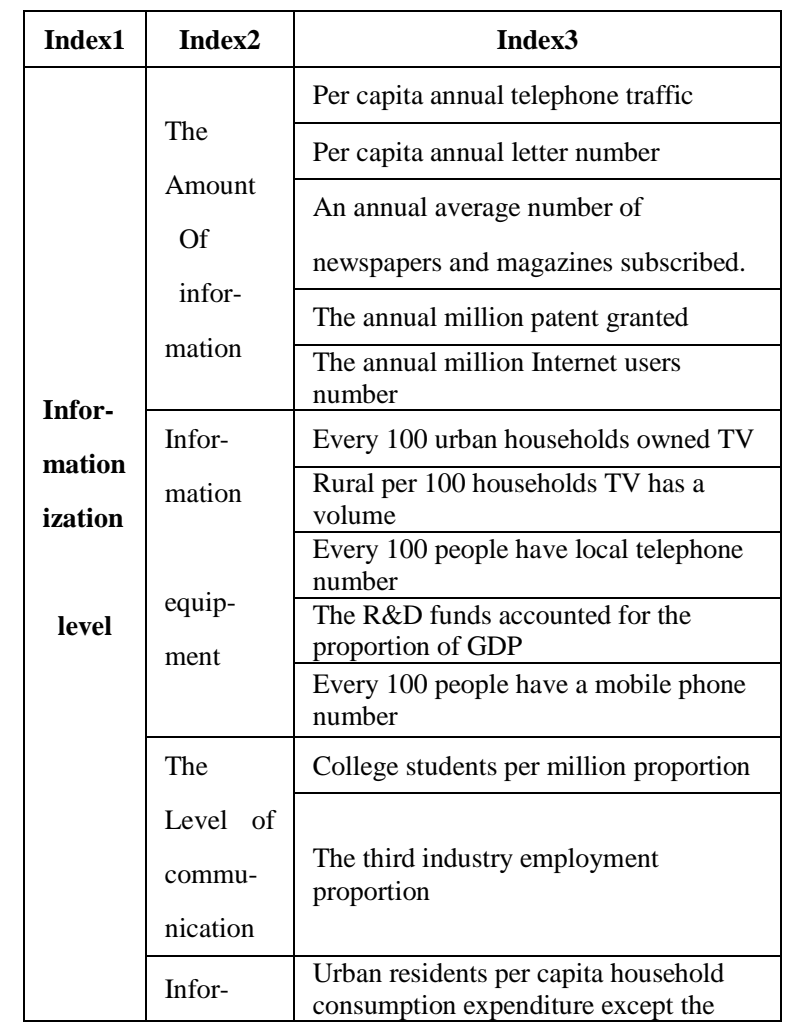

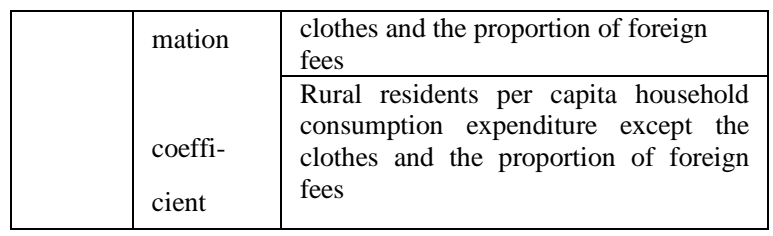

\section{2) Method to measure the Industrialization level}

For the limitations of a single measuring method, on the basis of the Theory of Clerk and Chenery, we establish the synthesized model to measure the industrialization level, as below:

$$
\begin{gathered}
\text { Industrializing indicator } \\
=(\text { industrialized output index }+ \text { industrialized } \\
\text { employee index }+ \text { per capita GDP }) / 3
\end{gathered}
$$

In this formula, the "industrialized output index" = the output valued of Secondary industry/ the output value of Primary industry; the "industrialized employee index" = the number of employed persons in Secondary industry / the number of employed persons in Primary industry.

\section{B. The relative measuring method on industrialization and informationization}

The VAR model is expressed as below:

$$
\begin{gathered}
\mathbf{y}_{t}=\boldsymbol{\Phi}_{1} \mathbf{y}_{t-1}+\cdots+\boldsymbol{\Phi}_{p} \mathbf{y}_{t-p}+\mathbf{H} \mathbf{x}_{t}+\boldsymbol{\varepsilon}_{t} \\
t=1,2, \cdots, T
\end{gathered}
$$

In this formula, $\mathrm{y}_{\mathrm{t}}$ is the column vector of $\mathrm{k}$ dimension endogenous variables, $\mathrm{p}$ is the hysteretic order, $\mathrm{T}$ is the number of specimen. $\mathrm{k} \times \mathrm{k}$ matrix, $\Phi 1, \ldots, \Phi \mathrm{p}$ and $\mathrm{k} \times \mathrm{d}$ matrix $H$ is matrix of coefficients to be assessed. $\varepsilon_{t}$ is the disturbance column vector of $\mathrm{k}$ dimension matrix; synchronous correlation can be allowed among the vectors, but not relative to their own hysteretic value and the right variable of the equation.

\section{THE DATA ACQUISITION AND INDICTOR CALCULATION}

\section{A. Data Acquisition}

In this article, the data was selected according to timing order from 2001 to 2012; all the index values are acquired after sorting out and calculating the data which are from the statistical yearbooks of Shandong province. 


\section{B. Calculation on informationization index}

For the convenience of comparing the indictors and easy to calculate, the method used in this article is to turn the absolute indictors into comparative indictors, working out the average value to acquire the informationization value finally. The specific steps are as follows:

First, the based year must be chosen, and every indictor of based year is defined as 100 , and next, the indicators of the based year are divided by the indictors of other years to get the comparative indictors; the second step, using the two-step average method: first step, suppose that the indictors of four categories have the same contribution effect on the ultimate informationization index, then work on the average value of each category respectively; the second step, add up the average valued of four categories and then divide by 4 , to get the final informationization index value. According to the statistical yearbook of Shandong province from 2001 to 2012, the year of 2001 is identified as based year, each indictor in 2001 is defined as 100 , through sorting out and calculating, each index value is presented in Table II (only the data of first class and second class are provided for the limitation of length of article).

TABLE II RESULT OF CALCULATING INFORMATIONIZATION INDICTORS

\begin{tabular}{|l|l|l|l|l|l|}
\hline Year & \multicolumn{1}{|c|}{$\begin{array}{c}\text { IF } \\
\text { amount } \\
\text { indictor }\end{array}$} & $\begin{array}{c}\text { IF } \\
\text { equipping } \\
\text { indictor }\end{array}$ & $\begin{array}{c}\text { Commu } \\
\text { nication } \\
\text { indictor }\end{array}$ & $\begin{array}{c}\text { IF } \\
\text { coefficient } \\
\text { indictor }\end{array}$ & $\begin{array}{c}\text { IF } \\
\text { indicto } \\
\text { r }\end{array}$ \\
\hline 2001 & 100 & 100 & 100 & 100 & 100 \\
\hline 2002 & 118.05 & 147.96 & 117.19 & 105.11 & 122.08 \\
\hline 2003 & 163.05 & 458.72 & 140.31 & 107.11 & 217.30 \\
\hline 2004 & 183.34 & 521.01 & 162.55 & 108.66 & 243.89 \\
\hline 2005 & 197.06 & 572.06 & 188.88 & 110.22 & 267.06 \\
\hline 2006 & 252.75 & 628.03 & 206.70 & 112.25 & 299.93 \\
\hline 2007 & 303.46 & 681.06 & 217.78 & 108.59 & 327.72 \\
\hline 2008 & 392.81 & 729.38 & 229.02 & 105.40 & 364.15 \\
\hline 2009 & 494.76 & 788.62 & 235.40 & 106.54 & 406.33 \\
\hline 2010 & 618.41 & 827.70 & 238.34 & 111.35 & 448.95 \\
\hline 2011 & 616.94 & 851.58 & 239.43 & 109.35 & 454.32 \\
\hline 2012 & 708.42 & 877.79 & 240.90 & 109.83 & 484.24 \\
\hline
\end{tabular}

\section{Calculation of industrialized indictors}

Take 2001 as the based year, and the ratio of indicator data of every year on that of 2001, multiplying 100 to get the industrialization indictors of every year. Based on the relative data from 2001 to 2012, according to Formula (1), the industrialized indictors are presented in Table III.

TABLE III THE RESULT OF CALCULATING INDUSTRIALIZED INDICTORS

\begin{tabular}{|l|l|l|l|l|}
\hline Year & $\begin{array}{c}\text { Industriali } \\
\text { zed output } \\
\text { indicator }\end{array}$ & $\begin{array}{c}\text { Indictor of } \\
\text { employed } \\
\text { persons in } \\
\text { industry }\end{array}$ & $\begin{array}{c}\text { Per } \\
\text { capita } \\
\text { indictor }\end{array}$ & $\begin{array}{c}\text { Industriali } \\
\text { zed } \\
\text { indicator }\end{array}$ \\
\hline 2001 & 100 & 100 & 100 & 100 \\
\hline 2002 & 111.31 & 108.65 & 111.25 & 110.40 \\
\hline 2003 & 130.69 & 122.28 & 130.15 & 127.71 \\
\hline 2004 & 142.26 & 136.10 & 160.90 & 146.42 \\
\hline 2005 & 159.24 & 165.86 & 195.28 & 173.46 \\
\hline 2006 & 175.42 & 175.81 & 231.32 & 194.18 \\
\hline 2008 & 174.19 & 192.23 & 270.58 & 212.34 \\
\hline 2009 & 174.63 & 184.97 & 322.98 & 227.52 \\
\hline 2010 & 174.80 & 191.84 & 351.93 & 239.53 \\
\hline 2011 & 176.62 & 200.88 & 402.06 & 259.85 \\
\hline 2012 & 180.34 & 216.26 & 462.81 & 286.47 \\
\hline
\end{tabular}

\section{RESULTS AND ANALYSIS}

\section{A. Checking unit root}

To avoid the "false regression", it is necessary to check the stability of $\ln X$ and $\ln Y$, and various methods can be used, such as DF, ADF, and PP. In this article, taking the common ADF to check the unit root, by Eviews6.0.

From the results, $\ln X$ and $\ln Y$ have unit root, but not stable. Through first order difference under 10\% level of significance, $\triangle \ln X$ is stable, but $\triangle \ln Y$ is not. And through the second order difference, both $\triangle 2 \ln X$ and $\triangle$ $2 \ln Y$ becomes stable, unit root vanishing, turning into second-order single integration serial

\section{B. Co-integration test}

From checking unit root, $\Delta 2 \ln X$ and $\Delta 2 \ln Y$ are stable timing array, which be the foundation of co-integration test; 
therefore, through co-integration test, the equilibrium relationships in long term between informationization and industrialization can be analyzed. The checking method include EG(Engle-Granger) based on the Regression residuals, and Johansen-Juselius based on vector auto-regression. In this article, $\mathrm{JJ}$ is adopted.

First, build up the VAR model, and check the residuum by $\mathrm{ADF}$; second, for the residuum does not contain constant and timing trend term, so only its original array can be checked, taking AIC and SC to make ADF test, after analyzing the lag coefficient, the lag phrase is finally defined as 2 . the P-Vlaue is $0.4744>0.05$ in the hypothesis for only one co-integration test equation, so the original hypothesis can not be denied, showing that there is only one co-integration test equation between informationization and industrialization, which indicates that informationization and industrialization have the dynamic equilibrium relationship in long term. The estimate result is shown in TableIV.

TABleIV Estimate Results AFter Co-INTEGRATION TEST

\begin{tabular}{lccc}
\hline \multicolumn{2}{c}{ Normalized cointegrating coefficients (standard error in parentheses) } \\
\hline \multicolumn{2}{c}{$\boldsymbol{L N \boldsymbol { Y }}$} & $\boldsymbol{L N} \boldsymbol{X}$ & $\boldsymbol{C}$ \\
\hline 1.000000 & 0.199355 & 1.801388 \\
& $(0.02564)$ & $(0.00692)$ & \\
\multicolumn{1}{l}{ C Cointegrating Equation(s): } & Log likelihood & 47.24940 \\
\hline
\end{tabular}

That is to say, the influence coefficient of informationization on industrialization is 0.199, after checking on the $5 \%$ level, the statistical effect is very notable. In long term, as the informationization level increases $1 \%$, the industrialization level would increase $0.199 \%$

\section{Granger causality test}

Only on the condition that the timing array is stable or there is co-integration relation among non-stable array, the Granger causality test can be used. Because the array of informationization and industrialization is not stable, on the basis of VAR model, after correcting it, the Granger causality test can be done, and the result, the optimal lag period being 2 , is shown in Table $\mathrm{V}$.
TABLE V RESULT FROM GRANGER CAUSALITY TEST

\begin{tabular}{lccc}
\hline Null Hypothesis: & Obs & F-Statistic & Prob. \\
\hline LNX does not Granger & & & \\
Cause LNY & 22.8053 & 0.0031 \\
$\begin{array}{l}\text { LNY does not Granger } \\
\text { Cause LNX }\end{array}$ & & \\
\hline
\end{tabular}

The Table 5 shows that on the condition of $1 \%$ significant level, informationization is the Granger cause of industrialization, but instead not, which tells that informationization obviously promotes the development of industrialization, but industrialization does not play such a role in informationizaion development.

The Granger causality test only tells that there are Cause-and-effect relationship between informationization and industrialization, while distracter terms happen, it is necessary to use the impulse response function to analyze.

\section{Impulse response function}

The result of impulse response function is shown is Graph 1, lateral axis representing tracking periods, and vertical axis representing influencing degree of variables, the solid line representing timing route, the broken line representing the confidence interval of double plus-minus standard deviation.
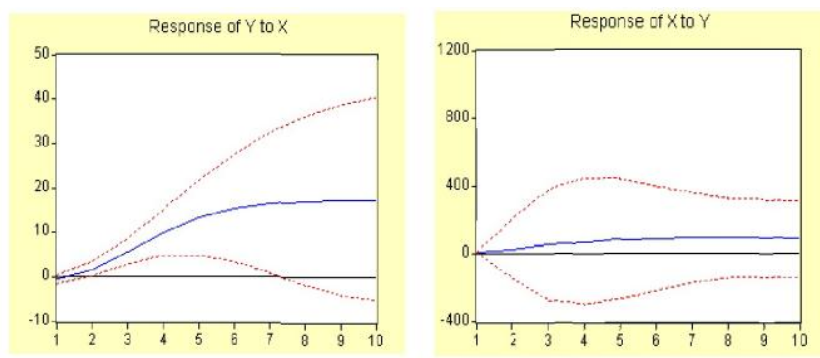

Figure 1. Impulse response function

From Figure1, in the beginning, the initialization of informationization is 0 after impulsing industrialization, and it increases gradually, and to the top in the 5th period, and then decreases slowly, and finally it became steady. This indicates that the development of informationization significantly aids the industrialization. On the other hand, the initialization of industrialization is 0 after impulsing informationization at the beginning, and it increases 
slowly, and to the top in the 6th period, and then decreases slowly, and finally it became steady. This tells that the development of industrialization can improve the informationizaiton level, but not so strong.

\section{E. Variance decomposition}

Variance decomposition is to analyze the rate of the estimated standard deviation of residuum after being impulse by various information, meaning the contributing rate of endogenous variable on standard deviation.

From the left part of Table 8, the industrialization affecting itself, from $100 \%$ at the beginning decreased to $9.61 \%$; and one unit of informationization impulsing industrialization from 0 at the initial period increasing to $9039 \%$ gradually, which tells that the informationizaiton is the ket factor of the development of industrialization. Form the right part of Table 8 , the change of estimated variance is $90 \%$ from itself varying. And one unit of industrialization impulsing informationization is very low, keeping $10 \%$ or, which tells that the impulse of industrialization is not the main factor to the informationization development, which is consistent to the result of Impulse response function analysis.

\section{THE CONCLUSION AND COUNTERMEASURES}

This paper calculates and interactive relationship of Shandong province industrialization and informationization index draws the following conclusion:

First, from year2001 to 2012, informatization and industrialization in Shandong have grown rapidly, and shows some characteristics of the fusion. Comparison of growth characteristics of informatization index and the index of industrialization from the view of development, they are complementary, and jointly promote the development, fusion. Since the "two integration" concept, the basic information and equipment level has increased substantially, make the informatization index increase, resulting in a strong impetus to the industrialization, energetically pull in per capita GDP and practitioners, index of industrialization began to steadily improve. But there are also shortcomings; eg.information on industrial output value of leading role is not obvious.
Second, there is a long-term stable relationship between the dynamic integration of informatization and industrialization in Shandong Province, but the relationship between symmetry is not strong. The informationization level increase $1 \%$ will drive the industrialization level increase $0.199 \%$. Informationization is the Grainger reason of industrial development, development of information to promote industrialization, but the development of industrialization is not information Grainger reason, drive the industrialization of information is not obvious. Illustrate the relationship between the fusion of industrialization and informatization in Shandong province asymmetry, only the two formed to promote the benign interaction between each other to achieve them better and faster development.

\section{ACKNOWLEDGMENT}

This is one of the research results of natural science fund project of shandong province which named "the research of low carbon industry system establishment in blue economic zone based on scenario analysis" (NO.ZR2011GM014), and Scientific research and development projects in shandong province colleges and universities (NO. J14WF69).

\section{REFERENCES}

[1]Zhou Zhenhua. The interaction and fusion of industrialization and informationization $[\mathrm{J}]$. China's manufacturing industry informatization,2008(01).

[2]Tong Youhao. The connotation of informatization and industrialization fusion, level and direction $[\mathrm{J}]$. Information Technology \& Standardization,2008(07).

[3]LI Jian. Two integration and information technology related concepts and relationships $[\mathrm{J}]$. Telecommunications Network Technology, 2010 (11).

[4]An XiaoPeng. The perspective of global industrial technology revolution of informatization and industrialization fusion $[\mathrm{J}]$. China Information Times, 2008 (2).

[5]XuJun. China's impact on the development of informatization and industrialization fusion factors and strategy research [D]. Huazhong University of Science and Technology, 2008.

[6]Jin Jiangjun. The combination of theoretical system [J] Informatization construction, 2009 (4) .

[7]Wang Jinjie. The implementation countermeasure research for the integration of informatization and industrialization [J]. Industrial \& Science Tribune, 2009 (11) .

[8]Wang Xiwei. Key elements of informatization and industrialization fusion and empirical research [J]. information science.2010(8).

[9]Ji DeShang, Zhang Shaoting. Depth of China's high-tech zone, informationization and industrialization fusion problem analysis $[\mathrm{J}]$. Journal of zhengzhou institute of light industry (social science edition).2012(05) 